\title{
Todos los Ismos el Ismo: Vallejo Rumbo a la Utopía Socialista
}

A propósito de Contra el secreto profesional y El arte y la revolución, Lima, Mosca Azul Editores, 1973.

La llegada de César Vallejo a Europa en julio de 1923 marcó el comienzo de una época decisiva en la vida del poeta, que duró hasta su primer viaje a Rusia en octubre y noviembre de 1928. Hacia fines de esta época sufrió una crisis intelectual y moral que iba a determinar, por un lado, el rechazo del surrealismo y de todos los ismos de la vanguardia, y por otro lado, su adhesión al marxismo y a la causa del proletariado, ejemplificadas en las luchas de éste en Rusia y en España. No representó ruptura alguna con su pasado, sino que, en lo literario, fue la fruición de varias lecciones de la experimentación trílcica y la búsqueda de una expresión más adecuada a las dimensiones sociales y fraternales del contenido poético que en aquel entonces quería expresar. Además, significó el rechazo de toda literatura que Vallejo no estimaba como expresión de los anhelos y las exigencias más profundas de una humanidad deshumanizada por la época en que vivia; y en lo ideológico, la fijación de su pensamiento socio-político (preocupación preeminente desde el poema titular de su primera obra, Los beraldos negros) en un marxismo más pragmático que dogmático, en el que vio Vallejo el camino que conduciría a la utopía socialista del porvenir.

Dos textos de Vallejo hasta ahora inéditos resultan fundamentales para estudiar el desarrollo del pensamiento de Vallejo durante este lustro: Contra el secreto profesional y El arte y la revolucion (Lima, Mosca Azul Editores, 1973). Vienen a complementar y a esclarecer la producción periodística y poética de Vallejo, no sólo la de esta época sino la de toda la última etapa de su vida. Además, parecen dar la clave para resolver algunas paradojas o contradicciones aparentes entre la estética y la ideología política de Vallejo.

Al hablar de la producción poética y periodística de estos años, cabe destacar el hecho de que a pesar de la crisis que sufrió, Vallejo no-dejó de escribir. Inició Hacia el reino de los Sciris, narrativa de tema incaico, que el autor fechó de $1924-1928^{1}$ En 1925 comenzó su

\footnotetext{
'Cl. los "Apuntes biográficos" sobre "Poemas en prosa" y "Poemas humanos", p. 7, que acompanan al la Obra poetica completa, edición facsimilar de Francisco Moncloa Editores, Lima, 1968. Citaremos en adclante" como Apuntes y $O P C$.
} 
colaboración periodística en la revista Mundial de Lima, y al año siguiente en la revista limeña Variedades, "quedando en cierta medida asegurada su situación material". 2 Al mandar tres poemas a Luis Alberto Sánchez en 1927 Vallejo se refirió a la "nueva cosecha", de su poesía, de la que estos poemas, al parecer, forman sólo una parte. ${ }^{3}$ Según lá viuda del poeta, Georgette de Vallejo, esta "cosecha"' constituye una etapa íntegra en la obra de Vallejo, la de Poemas en prosa, que figura como libro aparte, por primera vez, en la Obra poética completa. ${ }^{4} \mathrm{Y}$ empezó a elaborar el texto que recibiría el título de Contra el secreto profesional.

${ }^{2}$ Apuntes, p. 7 .

${ }^{3} \mathrm{Cf}$. Juan Espejo Asturrizaga, César Vallejo: itinerario del hombre, Lima: Libreria-Editorial Juan Mejia Baca, 1965 , quien reproduce los dos poemas, "Actitud de excelencia" y "Lomo de las sagradas escrituras", publicados en Mundial, 18 de noviembre de 1927. Además, reproduce parte del artículo de Luis Alberto Sánchez que los introduce (pp. 253-254). La carta con que Vallejo acompañó los poemas es reproducida en la p. 208. Según Juan Larrea, el tercer poema no publicado por Sánchez fue "Piedra negra sobre una piedra blanca" (cf. su artículo, "Claves de profundidad, Aula Vallejo, núm 1, Universidad de Córdoba, Argentina, 1961, p. 65).

${ }^{4} O P C$, pp. 223-271. Vallejo publicó en el mismo año de 1927 en Favorables-Paris-Poema, núm. 1, julio de 1926, revista que fundó el poeta con Juan Larrea, el poema "Me estoy riendo", el que, con "Lọmo de las sagradas escrituras", además de otro poema en verso, "He aquí que hoy saludo", aparecido en el último número de Favorables-Paris-Poema, núm. 2, octubre de 1926, figuran entre los Poemas en prosa, por ser de la misma época. Además se incluyen dos poemas en verso que son refundiciones de versiones primitivas en prosa: "Cuatro conciencias simultáneas" y "Entre el dolor y el placer" (los facsímiles de estos textos en prosa mecanografiados por el poeta fueron publicados por su viuda en la revista Visión del Perú, núm. 2, Lima, agosto de 1967). Todos estos poemas en verso, según Georgette, deben colocarse, por razones cronológicas, con los poemas en verso, escritos por los años 1923/24-1929, menos la versión definitiva de "Actitud deexcelencia", la que, con el título de "Altura y pelos"' fue colocada por Vallejo mismo en Poemas bumanos (Apuntes, p. 21). La primera edición de Poemas bumanos (Editions des Presse Modernes aux Palais Royal, Paris, 1939)' dio los 104 poemas inéditos de Vallejo (14 de los que están escritos en prosa) en el orden en que se encontraron a la muerte del poeta, no en el orden cronológico en que fueron escritos (Apuntes, p. 6). Además, de los 52 poemas fechados entre septiembre y noviembre de 1937, la mayoria fueron escritos antes, y las fechas corresponden "no a la creación del poema, sino a la de una simple revisión del mismo (y no forzosamente la última)" (Apuntes, p. 6). La Obra poética completa es la primera edición que pretende establecer el orden cronológico de los poemas, además de cumplir la voluntad del poeta, según Georgette de Vallejo, al publicar Poemas en prosa y España, aparta de mi este cáliz como libros independientes de Poemas humanos y los únicos que llevan los títulos que les puso el autor (Apuntes, p. 8). Desgraciadamente, la viuda de Vallejo no parece distinguir entre el título "Poemas en prosa" y el hecho de estar escritos ciertos poemas en prosa y otros en verso. Así que cuando dice que la primera edición de 1939 dió sólo “catorce poemas en prosa...por omisión inevitable de 'En el momento en que el tenista...' que, a la publicación de los versos póstumos de Vallejo, no figuraba en el conjunto de los poemas en prosa tal como lo había dejado el autor" (Apuntes, p. 19), para decir luego que figuran "dieciséis en la [Obra poética completa] con 'Lánguidamente su licor', también sustraído de 'Contra el secreto profesional' ", parece confundir el título del libro, Poemas en prosa, con el conjunto de poemas que se encuentran en el libro, puesto que hay, según nuestra cuenta, 19 poemas en total, de los que 13 están escritos en prosa y 6 en verso. De estos, 3 son los mencionados antes, "Me estoy riendo...", "Lomo de las sagradas escrituras" y "He aquí que hoy saludo...", los que la viuda no considera entre los inclúdos originalmente por el autor en Poemas en prosa. Así se explica el número 16. Pero para mayor confusión, el crítico José Miguel Oviedo, quien ha consultado los originales de Contra el secreto profesional que el diplomático peruano Federico Mould Távara, amigo de Vallejo en Paris, dió a la Biblioteca Nacional en 1973, declara que "Lánguidamente el licor" figura entre los manuscritos y que así se justifica la inclusión de este poema en prosa en Contra el secreto profesional, pero no en Poemas en prosa, donde lo colocó Georgette de Vallejo en la OPC. (Cf. José Miguel Oviedo, "Vallejo entre la vanguardia y la revolución [Primera lectura de dos libros inéditos]", Hispamérica, College Park, Md., EE. UU., núm. 6[abril 1974], 5). Al parecer, el número de poemas escritos en prosa que deben incluirse en Poemas en prosa queda reducido a 12, el número total de poemas en el libro a 18, 15 de los que debió incluir el poeta en la versión original del poemario, según el criterio de su viuda. Pero además de la confusión entre el título y la forma de los poemas, la viuda de Vallejo no nos da ninguna prueba textual de la "última voluntad" del poeta, y como señala Oviedo en su artículo, "demuestra que ha habido una manipulación excesiva de..[los] papeles vallejianos" (Hispamérica, p. 5). Por su parte, Americo Ferrari duda de que Poemas en prosa sea una "etapa perfectamente definida", puesto que por un lado, si "es muy probable que todos estos poemas 
A pesar de que prosiguió su producción literaria y periodistica, y de que por fin consiguió una relativa estabilidad económica, Vallejo pareció sufrir durante esta época de lo que su viuda ha llamado "un estado de inestabilidad y de descontento", que llegó a una "crisis aguda en 1927-1928" (A puntes, p. 7). La causa de tal crisis parece haber tenido sus raices en el "profundo malestar" que sentía el poeta ante su alejamiento de los problemas de la humanidad avasallada. Si al principio se resistió ver en el marxismo la solución a los males de los hombres, según afirma su viuda (Apuntes, p. 7), hacia 1928 empezó a experimentar una transformación intelectual que iba a llevarlo a fines del año a Rusia por primera vez.

Mientras experimentaba tal transformación en su ideología socio-política, Vallejo siguió criticando, en los artículos publicados en Mundial y Variedades, varios aspectos de la vida económica, socio-política, literaria y artística de la entreguerra europea. ${ }^{5}$ Hasta la fecha, estos artículos nos han ofrecido la fuente más rica y útil para estudiar el desarrollo del pensamiento de Vallejo durante esta época. Podemos ver, sobre todo, cómo llegó al rechazo de los movimientos vanguardistas, los que le ejemplificaron de alguna manera toda la cultura europea de la época. En su conjunto, estos artículos vienen a ser una condenación de la decadente cultura capitalista de occidente, condenación que, sin embargo, no incluyó ningún programa especifico para renovar o revolucionar esta cultura. La publicación tan largamente esperada de los dos textos más representativos del pensamiento vallejiano de esta época nos pone al alcance de una mayor comprensión de la visión literaria, cultural e ideológica que tenía el poeta, además de su concepto del hombre y de la sociedad del porvenir.

Según Georgette de Vallejo, al llegar Vallejo a Europa an 1923, emprendió varios trabajos literarios que iban a dar origen a tres obras: Hacia el reino de los Sciris, Poemas en prosa y Contra el secreto profesional (Contra el secreto profesional, p. 7; citaremos en adelante Contra el secreto). La primera mención de que existia tal libro es también de la

hayan sido escritos entre 1923 y 1928-30 [sic], resulta también indudable que por la misma época Vallejo escribia otros poemas en verso..." (Americo Ferrari, El universo poético de César Vallejo, Caracas, Monte Avila Editores, 1972 , p. 271 ; citaremos en adelante El universo poético). Además, señala Ferrari, estos poemas en verso los coloca Georgette de Vallejo en la etapa 'bien definida' de Poemas en prosa, 'mientras que 'Actitud de excelencia', que data de la misma época, sigue figurando, refundido y con el nombre de 'Altura y pelos', en la etapa 'bien definida' de Poemas bumanos" (El universo poético, pp. 271-272). Anade que no es nada improbable que diversos otros poemas que figuran en Poemas bumanos hayan sido escritos antes de 1930. "Tal sería el caso, por ejemplo, del célebre 'Piedra negra sobre una piedra blanca', que según Juan Larrea sería el tercer poema enviado por Vallejo a L. A. Sánchez en $1927 "$ (El universo poético, p. 272). A la vez que su viuda declara que fue Vallejo mismo quien colocó "Altura y pelos" en Poemas bumanos, afirma que el poeta colocó "En suma, no poseo para expresar mi vida sino mi muerte..." en Poemas en prosa antes de su muerte "por un descuido evidente" (A puntes, p. 6), lo que justificó, según la viuda, que lo devolviera ella a Poemas bumanos (donde figura en todas las ediciones de éste). Este poema parece una mezcla de versos y de prosa, y podríamos pedir más datos para establecer, sin duda alguna, una equivocación por parte del poeta (si es que aceptamos Poemas en prosa como libro aparte). De todos modos, parece difícil, si no imposible, establecer con certeza el orden cronológico de la obra poética de Vallejo escrita en Europa.

5Cf. la "Minima guía bibliográfica" preparada por Alfredo Roggiano, Revista Iberoamericana, XXXVI, núm. 71 (abril-junio 1970), pp. 353-358. Roggiano menciona las siguientes obras: Articulos olvidados (Lima: Asociación Peruana por la Libertad de la Cultura, 1960), prólogo de Luis Alberto Sánchez; Literatura y arte (Textos escogidos) (Buenos Aires: Ediciones del Mediodia, 1966); Aula Vallejo, núm. 1 (Universidad de Córdoba, Argentina, 1961) (pp. 21-51) y Aula Vallejo, núm. 5-6-7 (Universidad de Córdoba, Argentina, 1967) (pp. 47-87); Desde Europa, Crónicas y articulos dispersos (Lima: Institu to Porras Barrenechea, 1969) (Recopilación, prólogo y notas de Jorge Puccinelli). [El profesor Roggiano me informa que incluyó esa ficha en su bibliografía por indicación del recopilador, quien le mostró el manuscrito ya a punto de ser impreso. La no impresión se debió a causas ajenas al editor, que no es del caso exponer aqui.] 
viuda; en Apuntes, advierte que Vallejo pudo reunir, al regresar de su primer viaje a Rusia, estas tres obras bajo el título de Codigo civil. ${ }^{6}$ El texto de Contra el secreto profesional no incluye el artículo titular publicado en Variedades el 7 de mayo de 1927 (reproducido en Aula 1, pp. 32-35). Este, a propósito del poeta y compatriota de Vallejo, Pablo Abril, pretende caracterizar a la "nueva poesía" de América (Neruda, Borges, Maples Arce, etc.), la que, declara Vallejo, imita servilmente a la vanguardia europea. El título alude, sin mencionarlo, al libro de Jean Cocteau, Le secret professionnel, aparecido en París en 1922, texto crítico en el que Cocteau propone un tipo de código literario como manera de reclamar cierto orden dentro del caos de movimientos literarios de esta época (se integró luego en un volumen titulado precisamente Rappel à l'ordre, de 1926). Cocteau nos presenta al artista divinizado, egoista, de "buen gusto", quien busca las formas perfectas y gratuitas, sin mezclar la literatura con la impura realidad, y quien, por eso, rechaza las urgencias de la época en que le toca vivir, sobre todo las exigencias morales de la humanidad que sufre de esta época. Nada más lejos de los conceptos literarios de Vallejo, como veremos.

La omisión de este artículo implica otra significación más amplia del título, sobre todo cuando advertimos que Vallejo tituló así al libro sólo después de regresar de su primer viaje a la Unión Soviética, y más de un año después de publicar el artículo. Ahora el título tendrá un sentido general, que no se aplica sólo a lo literario, sino a cualquier actividad del hombre que lo fracciona, que lo separa del prójimo y que así lo deshumaniza. En las palabras de Vallejo:

"Los técnicos hablan y viven como técnicos y rara vez como hombres. Es muy difícil ser técnico y hombre, al mismo tiempo. Un poeta juzga un poema, no como simple mortal, sino como poeta. Y ya sabemos hasta qué punto los técnicos se enredan en los hilos de los bastidores, cayendo por el lado flaco del sistema, del prejuicio doctrinario o del interés profesional, consciente o subconsciente y fracturándose así la sensibilidad plena del hombre" (Contra el secreto, p. 38).

Se trata de una preocupación, si no obsesión, que subyace bajo todos los temas del libro: la conciencia angustiosa de la fragmentación de la existencia. De ahí la dificultad del hombre de alcanzar la plenitud humana, una plenited orgánica. Todos los otros temas tienen sus raices en esta obsesión: el dolor como valor positivo, el absurdo (también de valor positivo), la fuerza destructiva del egoísmo, la búsqueda de la solidaridad humana, el tema del doble como obsesión y salvación, y quizá más importante para Vallejo, el artista, la importancia de

\footnotetext{
6 Hay cierta confusión en lo que dice Georgette de Vallejo: "Al terminar el año [1928], Vallejo, que ya radica de nuevo en París, procede a la selección de 'Código Civil', título que reúne por entonces tres obras. Dos en prosa: la una, ya titulada 'Hacia el reino de los Sciris', y la otra, que titulará 'Contra el secreto profesional'. La tercera la constituyen unos poemas en prosa. Son estos mismos los que integrarán 'Poemas en prosa', publicado con 'Poemas humanos' y 'España, aparta de mí este cáliz', en un solo volumen (París, julio de 1939). Luego de esta selección, desaparece definitivamente 'Código Civil' "'. Americo Ferrari señala la importancia del matiz de significado entre "unos poemas en prosa y el título, Poemas en prosa. Si se trata de un verdadero libro con tal título, "¿cómo se entiende que en la primera edición de Poemas humanos esos poemas hayan perdido su carácter de libro aparte y su títılo?' (El universo poético, p. 273). En cuanto a éste y los demás errores de la edición original de Poemas bumanos, ha declarado la viuda del poeta: " "...mi excesiva fidelidad a los originales me llevó a respetar ciegamente el éstado en que Vallejo había dejado sus textos poéticos..." (Apuntes, p. 5; cf. también p. 6). Al parecer, Vallejo, al dejar sus poemas, a su muerte, en un "orden indeterminado", no creía inminentes ni su publicación ni su propia muerte.
} 
la palabra como signo del pacto social entre los hombres. O sea, por medio de esta obra, podemos comprobar que algunas de las preocupaciones principales de Vallejo en Los heraldos ziegros y Trilce siguen siendo los temas básicos al emprender el poeta la última etapa de su producción literaria.

Como muchos pasajes del libro, el citado arriba proviene de los articulos publicados en Mundial y Variedades entre 1925 y 1929 , refundidos drásticamente, sobre todo por la eliminación de las actualidades que dieron lugar a estas meditaciones del autor. Además de tales pasajes, se agregan otras notas y observaciones, unas de las que podría considerarse como trozos o esbozos de poemas en prosa, otros poemas en prosa que parecen tener sus formas definitivas, ${ }^{7}$ y una serie de lo que podríamos denominar parábolas, algo semejantes a las del Nuevo Testamento, pero que nos recuerda más, por ser de índole secular, las de Kafka y Borges. Por fin, la viuda de Vallejo ha agregado al final "unas notas sobre preocupaciones afines, recopiladas de las libretas de apuntes dejadas por César Vallejo" (prefacio, Contra el secreto, p. 7).

Es imposible determinar si Contra el secreto profesional, escrito "paralelamente" a Poemas en prosa (prefacio, p. 7), podría considerarse en su forma definitiva tal como se presenta, a pesar de lo que dice Georgette de Vallejo en Apuntes: "Vallejo no ha dejado ni una sola obra (versos o prosa) que no estuviera prácticamente terminada e inclusive repetidamente revisada..." (p. 16). Por su forma "abierta", tal pregunta no es quizás la más importante. Lo que sí importa es la oportunidad que nos da este texto de seguir de cerca el desarrollo del pensamiento de Vallejo durante esta época.

A pesar de la continuidad de temas, no encontramos en Contra el secreto profesional la expresión tan hermética de Trilce, aunque sí una expresión del todo personal, la que podría llevar al lector a ciertas conclusiones erróneas si no estuviera familiarizado con la expresión poética de Vallejo. Es el caso, sobre todo, cuando se trata de lo absurdo, que podría interpretarse como valor negativo. Así, por ejemplo, a primera vista el pasaje siguiente parece ser una condenación de todo lo que no se conforma a las normas lógicas de la vida :

Se rechaza las cosas que andan lado a lado del camino y no en él. ¡Ay del que engendra un monstruo! ¡Ay del que irradia un arco recto! iAy del que logra cristalizar un gran disparate! Crucificados en vanas camisas de fuerza, avanzan así las diferencias de hojas alternas hacia el panteón de los grandes acordes"'.

(Contra el secreto, p. 39) ${ }^{8}$

${ }^{7}$ En el prefacio a Contra el secreto profesional, p. 7, la viuda dice que tres poemas han pasado a Poemas en prosa. Pero José Miguel Oviedo, quien ha consultado los únicos manuscritos existentes fuera de los que posee la viuda del poeta (cf. nota 3), ha averiguado que Vallejo quiso incluir "Lánguidamente su licor" en Contra el secreto profesional, donde figura en esta edición, y que no debió incluirse en Poemas en prosa, de la OPC. Al parecer, Vallejo quiso pasar otros dos poemas en prosa a esta obra " En el momento en que el tenista" (versión poética de "De Feuerbach a Marx" que aparece en Contra el secreto profesional), y "Cuatro conciencias". Véase José Miguel Oviedo, "Vallejo entre la vanguardia y la revolución", p. 5.

8josé Miguel Oviedo no parece entender bien este pasaje cuando lo califica de "retroceso" a los "acentos de Trilce" y lo contrapone a otros en que "razona dialécticamente" Vallejo. Es nuestro juicio de que este pasaje es también dialéctico, como explicamos luego. Cf. José Miguel Oviedo, "Vallejo entre la vanguardia y la revolución", p. 7. Afirma, además, que la obra en su totalidad muestra "avances y retrocesos que testimonian la complejidad del proceso en el que, como artista y como hombre Vallejo se ha envuelto" (p. 7). A nuestro parecer, el proceso es complejo porque abarca tantos campos de la cultura, no porque hay irresolución por parte del autor. 
Tal pasaje es algo obscuro porque Vallejo parte de un presupuesto implícito: el del materialismo dialéctico como método filosófico, el que conduce, por medio de una síntesis de contrarios, hacia "los grandes acordes", frase positiva por completo, que nos hace entender " "panteón" también en forma positiva, quizás en el sentido de los nuevos seglares "dioses" salvadores de la humanidad, que serían los propios "grandes acordes". La palabra clave es "vana', ; nada ni nadie podrá impedir tal proceso. Los "ayes" nos recuerdan el poema LXXIII de Trilce: "Ha triunfado otro ay. La verdad está alli./"'(OPC, p. 215). Pero además la frase "ay de..." parece aludir a la amenaza al orden establecido, sobre todo al capitalismo decadente que hasta la fecha ha podido triunfar por medio de la ley darwiniana de la supervivencia de los más aptos. Así se explica el sentido del pasaje siguiente, "La cabeza y los pies de la dialéctica", en que podemos ver la esperanza de Vallejo que siempre está por debajo de todo sufrimiento:

Ante las piedras de riesgo darwineano, de que están construidos los palacios de las Tullerías, de Potsdam, de Peterhof, el Quirinal, la Casa Blanca y el Buckingham, sufro la pena de un megaterio, que medítase parado, las patas traseras sobre la cabeza de Hegel y las delanteras sobre la cabeza de Marx.

\section{(Contra el secreto, p. 19)}

El materialismo dialéctico de Marx, el que ha reemplazado definitivamente al idealismo dialéctico de Hegel, viene a ser la solución tan esperada del callejón sin salida de la lógica clásica, la que sirve de fundamento a la cultura capitalista de occidente y la que ha conducido a la decadencia de ésta. Así lo expresa Vallejo en un pasaje en que parece criticar a la ciencia y el "sentido común"' de la lógica cotidiana, a la vez que parece elogiar el arte y lo que él denomina "la conciencia dialéctica de las cosas", frase que parece conducir a las paradojas y contradicciones de lo absurdo:

Existen preguntas sin respuestas, que son el espíritu de la ciencia y el sentido común hecho inquietud. Existen respuestas sin preguntas, que son el espíritu del arte y la conciencia dialéctica de las cosas.

\section{(Contra el secreto, p. 18)}

Se ve aquí que la función del arte es la de rescatar la vida humana del espíritu científico analítico que la destruirá junto con el universo mismo en nombre del conocimiento humano. Para Vallejo el mayor conocimiento, imprescindible para el hombre, es la visión orgánica y sintética que dan el arte y el materialismo dialéctico como modo de pensar.

Pero es en la parte del trabajo intitulado "Negaciones de negaciones" donde se comprende mejor la importancia que otorga Vallejo a las paradojas y los "grandes disparates" de lo absurdo. Nos da seis ejemplos de casos raros o de situaciones absurdas, todos los que se incluyen con otras materias en su artículo, "Las pirámides de Egipto", aparecido en Mundial, 26 de marzo de 1926 (reproducido en Articulos olvidados, pp. 7477). Pero en la versión refundida suprime precisamente el pasaje que explica el sentido que en aquel entonces tenía para Vallejo el sin-seńtido; antes de que descubriera su resolución dialéctica, parecía intuir la existencia de alguna solución fuera de la lógica normal:

En el fondo, no se trata de otra cosa que de modos de intuición tan antiguos como el mundo...es entre los niños que tales métodos heroicos de aventura creadora o 
de descubrimiento, son más frecuentes. Entre los niños y entre los locos. Entre los hombres, no, porque los hombres tienen la inclinación a ir sobre seguro, esto es, por las vías inmediatas de la realidad lógicamente practicable. Los hombres son muy maliciosos y demasiados prácticos, para fiarse de tales aventuras de intuición de que tratamos...

(Artículos olvidados, p. 75)

Como dice Vallejo en otro lugar, "Dichosos ellos que, al menos, pueden así divorciarse de las necesidades de la lógica" ("La inoculación del genio", Articulos olvidados, p. 194). La época en que Vallejo escribe demuestra el fracaso del pensamiento lógico de occidente. A los seis ejemplos sigue un poema en prosa o tipo de letanía sin titulo que revela un mundo congelado por completo por la racionalidad que plantea al hombre como un ser escindido en dos, un cuerpo y una psique, escisión que conduce al hiato fatal entre la lógica y la existencia verdadera del ser humano:

Los trescientos estados de mujer de la Tour Eiffel, están helados. La herzciana crin de cultura de la torre, su pelusa de miras, su vivo aceraje, engrapado al sistema moral de Descartes, están helados.

\section{(Contra el secreto, p. 35)}

El poema continúa citando una aparente serie caótica de cosas, pero si las consideramos bien, vemos que se trata de la condenación de la cultura de occidente, de sus instituciones y de su total cosmovisión. La historia:

Las estatuas que periplan la Plaza de la Concordia y sobre cuyos gorros frigios se oye al tiempo estudiar para infinito, están helados.

(Contra el secreto, p. 36)

La religión:

Los dados de los calvarios católicos de París, están helados hasta por la cara de los treses (p. 36) ${ }^{9}$

La vida cívica y política:

Los gallos civiles, suspenso en las agujas góticas de Notre-Dame y del Sacré-Coeur, están helados (p. 36).

La vitalidad de la juventud:

${ }^{9}$ Como han señalado varios críticos, el número tres, por ser impar, evade la fatalidad simétrica de lógica. En otro lugar he indicado la posibilidad de que el número tres apunta hacia una nueva dimensión más allá de las dimensiones del tiempo y del espacio. Cf. mi tesis doctoral, "The Poetic Vision of César Vallejo in Los beraldos negros and Trilce", aún inédita (University of Pittsburgh, 1969). Hay también un aspecto dialéctico, puesto que es la síntesis del guarismo 1 que representa la unidad y lo único y el guarismo 2 que simboliza la multiplicidad (el uno y él otro) e implica todos los demás guarismos. Implica también el concepto de la trinidad con todo su sentido noumenal, aunque dudamos de que tenga el sentido ortodoxo del cristianismo, por la evidencia misma de pasajes como el citado arriba. Sobre el número en Vallejo, cf. también mi artículo, "Babel y lo babilónico", Aproximaciones a César Vallejo, simposio dirigido por Angel Flores (New York: Las Américas Publishing Co., 1971), II, pp. 61-54. 
La doncella de las campiñas de París, cuyo pulgar no se repite nunca al medir el alcance de sus ojos, está helada (p. 36).

El arte contemporáneo:

El andante a dos rumbos de "El pájaro de fuego"' de Strawinsky, está helado (p. 36).

La ciencia:

Los garabatos escritos por Einstein en la pizarra del anfiteatro Richelieu de la Sorbona, están helados (p. 36).

La tecnología moderna:

Los billetes de avión para el viaje de París a Buenos Aires, en dos horas, 23 minutos, 8 segundos, están helados (p. 36).

La fuente misma de la energía:

El sol está helado (p. 36).

La Naturaleza de la que vive el hombre:

El fuego central de la tierra está helado (p. 36).

Por fin, el hombre mismo, en todos sus aspectos biológicos y espirituales:

E1 padre, meridiano, y el hijo, paralelo, están helados.

Las dos desviaciones de la historia están heladas.

$\mathrm{Mi}$ acto menor de hombre está helado.

Mi oscilación sexual está helada (p. 37).

Si la obsesión o preocupación constante del libro es la conciencia de la fragmentación de la vida, el libro entero representa un esfuerzo para lograr, por medio del arte, un nuevo enfoque del mundo y del hombre, y de esta manera superar la dicotomía racionalista. El artista debería buscar nada menos que la unidad secreta de la existencia; de ahí su grave responsabilidad social y moral. No debe, no puede, buscar " el secreto profesional" que lo separe de los otros hombres, sino que debería darles a los otros el conocimiento esencial que les otorga el verdadero arte. Es por eso que Vallejo revela a lo largo del libro tanto interés en la estética teatral, plástica y cinemática, pero sobre todo en la poética. El idioma poético, drama central de Trilce, sigue siendo un tema básico de Vallejo. Por la insuficiencia del lenguaje, el poeta se ve obligado a llenar los huecos de la expresión, o sea, darles a las cosas sus verdaderos nombres. Es el sentido de varias parábolas y pasajes 
sueltos. En la parábola, "Teoría de la reputación," el preso, víctima de la opresión económica y oficial, no tiene nombre. La vida humana es orgánica, o debería serlo, y debería conducir a la expresión total del ser humano, en el "acto representativo" que sintetice esta vida. Por representar el nombre esta vida, mientras ésta no se realiza, el verdadero nombre del hombre no puede darse. Además, parece estar implícito aquí el concepto de que el poner nombre a lo que no existe es falsear la existencia y traicionar el lenguaje ("el secreto profesional" literario por definición).

Otra parábola, "Magistral demostración de salud pública", plantea de otra manera el problema del lenguaje. En ésta, el narrador crea una lengua, mejor dicho, un vocabulario poliglota. Su eficacia se encuentra "en el hecho de estar formado en sus tres cuartas partes sobre raíces arias y el resto sobre raices semitas" (Contra el secreto, p. 58), o sea, sobre familias lingüísticas que entre sí representan la herencia cultural (mítica, literaria y lingüística) de occidente. El enorme alcance simbólico de la expresividad es quizás lo más importante en este caso, pero habrá que reconocer también la fusión simbólica de estos dos grupos lingüísticos (y por lo tanto de sus culturas) en una nueva síntesis dialéctica.

Lo anecdótico de la parábola es mínimo pero fundamental: el deseo del narrador de expresar una experiencia que tuvo en el Hotel Negresco de Niza queda frustrado por su absoluta incapacidad de encontrar la forma literaria que le sirva para expresarla:

Sin duda, existen cosas que no se ha dicho ni se dirá nunca o existen cosas totalmente mudas, inexpresivas e inexpresables. Existen cosas cuya expresión reside en todas las demás cosas, en el universo entero, y ellas están indicadas a tal punto por las otras, que se han quedado mudas por sí mismas.

(Contra el secreto, p. 53 )

Esta característica alusiva de los vocablos es lo esencial; no le interesa al narrador las ideas o conceptos preestablecidos de las palabras, sino la forma o sonido de cada vocablo, que él busca llenar de nuevos significados. Se trata, desde luego, de la renovación del lenguaje, pero en este caso, de una renovación tan radical como el rechazo de la lógica como método válido de pensar. Como es de esperar, en el fondo yace el problema de la lógica como método incapaz de expresar cabalmente todo lo que no se somete a la razón: los sentimientos, las emociones, la unidad esencial de la existencia. En otras palabras, es el problema gnoseológico de siempre, expresado desde el principio de la trayectoria poética de Vallejo en el "yo no sé", del poema titular de Los beraldos negros. Saber es nombrar, lo que supone un lenguaje capaz. Desde otro aspecto, las paradojas y las contradicciones son problemas lingiiisticos, porque la existencia es unitaria en el fondo. El problema es el de captar linguiisticamente esa unidad. Es decir, se trata de una poética.

El hecho de que, por fin, el narrador pudo dar forma literaria a su experiencia por medio de una lista de vocablos tomados de ocho idiomas (no por voluntad del narrador sino por la de los vocablos mismos, los que iban presentándosele "espontáneamente" al oído del narrador), significa que los "materiales léxicos", capaces de dejarle expresarse al hombre sí existen, si el hombre sabe encontrarlos (la tarea poética por definición). Puesto que el bienestar de los hombres depende precisamente de ponerles nombres a las cosas, de 
saber la verdad, esta anécdota viene a ser "una magistral demostración de salud pública". Una variación de tal poética se da en un pasaje sobre la posibilidad de transportar al poema la estética de Picasso:

Es decir: no atender sino a las bellezas estrictamente poéticas, sin lógica, ni coherencia, ni razón. Como cuando Picasso pinta a un hombre y, por razones de armonía de líneas o de colores, en vez de hacerle una nariz, hace en su lugar una caja o escalera o vaso o naranja.

(Contra el secreto, p. 74)

Algo semejante parece ser la poética inspiradora de por lo menos dos composiciones de Poemas bumanos, "La paz, la abispa, el taco..." y "Transido, salomónico...".

En todas las artes Vallejo busca lo orgánico como piedra de toque. En la danza, busca la improvisación que, al morir en seguida, evita llegar a ser estereotipada por consecuencia de la repetición. "Esto hacen los negros", es decir, los más espontáneos por ser los menos contagiados por la cultura de occidente (Contra el secreto, p. 39). En el teatro, hace falta una estética orgánica:

Si no se quiere que el teatro, como representación, desaparezca, convendría, al menos, que cada pieza sea improvisada--texto, decorado, movimiento escénico-por los actores mismos, que, al efecto, deben ser también autores y "régisseurs", de las obras que representan. Tal hace Chaplín en la pantalla.

(Contra el secreto, p. 40$)$

Otra variación:

...una pieza en que el autor convive, él y su familia y relaciones, con los personajes que él ha creado, que toman parte en su vida diaria, sus intereses y pasiones. No se sabe o se confunden los personajes teatrales con las personas vivas de la realidad.

(Contra el secreto, p. 94)

Cabe subrayar una vez más la importancia del arte en la cosmovisión vallejiana. Como se puede ver por los ejemplos aludidos, para Vallejo sólo el arte, por medio del método dialéctico, puede dar "las respuestas sin preguntas", las afirmaciones sintéticas de la unidad y la totalidad de la existencia humana. La pregunta que conduce a tal respuesta sintética no existe, precisamente porque la pregunta, por definición, plantea una visión analítica de la realidad al aislar forzosamente sólo ciertos elementos de esa realidad.

El ejemplo del espiritu sintético del arte y "la conciencia dialéctica de las cosas" señala una manera de rescatar el pasado y de hacerlo instaurarse en el presente; en otras palabras, de rescatar la unidad de la historia. Tal parece ser el sentido del ensayo breve, "Explicación de la historia", una refundición del artículo "El secreto de Toledo", publicado en Mundial, 25 de junio de 1926 (reproducido en Articulos olvidados, pp. 92 - 
95). Aquí Vallejo ve el pasado como siempre presente en "la actualidad viajera, que a la postre, es la refundición y cristalización esencial de la historia pasada" (Contra el secreto, p. 16). En otro ensayo, "El movimiento consustancial de la materia', Vallejo niega aún más enfáticamente toda ficción lógica (en este caso la "ilusión geométrica" de las paralelas y la "ilusión temporal" de la pluralidad) que pretende dividir la unidad de la historia y la naturaleza: "...se desenvuelven linealmente y, en esta única línea, solitaria, los hechos humanos y los fenómenos naturales se suceden, uno tras otro, sucesiva y nunca simultáneamente"' (p. 23). La pluralidad resulta un fenómeno del tiempo y no del espacio, puesto que "el número 1 está solitario de lugar' y el 2 y todos los guarismos subsiguientes existen como figuraciones abstractas del pensamiento y no como "realidad objetiva" (p.

24). El ensayo representa un esfuerzo por redimir la historia para llegar a la unidad:

"Bajo la ilusoria simultaneidad de las cosas y los seres, reposa, en el fondo, la realidad exclusivamente sucesiva y en marcha del universo"' (p. 25).

Pero Vallejo no acepta el determinismo dialéctico como válida ley que gobierne "esta única línea"' que es la historia, a pesar de que reconoce a Hegel y a Marx como descubridores de la ley dialéctica: " [Mi] posición rebasa la simple observancia de esta ley y llega a cabrearse contra ella y llega a tomar una actitud crítica y revolucionaria delante de este determinismo dialéctico", (p. 99). De ahí su actitud comprometida como artista, actitud que sin embargo nunca llegó a desvirtuar su arte, es decir, su expresión poética, aunque sí influyó enormemente en su producción periodística posterior (por no decir producción en prosa, puesto que Vallejo se expresaba poéticamente en prosa no solamente en "una etapa bien definida", sino a lo largo de su vida, como demuestran muchos momentos de la obra aquí analizada).

La búsqueda de la unidad del hombre se expresa más sintéticamente en el párrafo en prosa "De Feuerbach a Marx", pasado luego en verso para integrarse a Poemas bumanos bajo el título de "En el momento en que el tenista...". E1 rechazo de la dicotomía de Descartes es implícito:

Cuando un órgano ejerce su función con plenitud, no hay malicia posible en el cuerpo. En el momento en que el tennista [sic] lanza magistralmente su bola, le posee una inocencia totalmente animal. Lo mismo ocurre con el cerebro. En el momento en que el filósofo sorprende una nueva verdad, es una bestia completa. Anatole France decía que el sentimiento religioso es la función de un órgano especial del cuerpo humano, hasta ahora desconocido. Podría también afirmarse que, en el momento preciso en que este órgano de la fe funciona con plenitud, el creyente es también un ser desprovisto a tal punto de malicia que se diría un perfecto animal.

(Contra el secreto, p. 13)

El término "animal", en el léxico de Vallejo, es el más alto elogio que puede emplearse, puesto que señala lo orgánico y lo natural del sujeto. Falta por completo en tal momento la malicia, o sea, la enajenación que conduce a la perversidad.

En otro pasaje, Vallejo hace más explícita su disconformidad con la exaltación de la razón, fuente de la enajenación humana: 
Se puede hablar de freno sólo cuando se trata de la actividad cerebral, que tiene el suyo en la razón. El sentimiento no se desboca nunca. Tiene su medida en sí mismo y la proporción en su propia naturaleza. E1 sentimiento está siempre de buen tamaño. Nunca es deficiente ni excesivo. No necesita de brida ni de espuela.

(Contra el secreto, p. 42 )

La enajenación trae irrefragablemente consigo la traición del lenguaje, y como ya hemos notado, la falsificación del lenguaje tiene por resultado la perdición del hombre. La subversión de la palabra es a la vez la subversión del conocimiento del hombre. En una anécdota Vallejo describe el momento en que por primera vez un niño descubre el sexo de su madre. Al señalarlo, experimenta un manotazo y la reprobación materna. Así empieza el abandono de la fe en la palabra:

El chico vio, sin embargo, una cosa existente y su conocimiento fue roto y controvertido por su propia madre, cuya palabra le merecía toda fe. Aquí está la raíz de la farsa social y de los fracasos de la historia y de las luchas entre los hombres.

(Contra el secreto, pp. 93-94)

Años antes de escribir esto, en Trilce XX, Vallejo había señalado lo temprano que aprende el ser humano a traicionar la palabra:

La niña en tanto pónese el índice

en la lengua que empieza a deletrear

los enredos de enredos de los enredos. . .

$$
\text { (OPC, p. 162) }
$$

Este poder de la palabra de esconder la verdad es quizás el sentido de la parábola "Vocación de la muerte", en la que el hijo de María viene a ser paria entre los miembros de su propia familia, además de serlo entre los vecinos del pueblo, y ya no trabaja de carpintero para ganar la vida. Desaparece largos ratos en el desierto, cuida a las pobres fieras que encuentra allá, y por fin, negada la ayuda familiar, muere de hambre, olvidado de todos. En el mismo momento de morir el hijo de Maria, se nombra a un joven filosofastro "Hijo del Hombre, enviado del Padre, el Mesías". Desde luego es irónico el que el pueblo no se dé cuenta de la verdad. El hijo de María, con su "vocación de la muerte", ha visto la tragedia de la vida humana, y por eso merece ser llamado Hijo del Hombre, por reconocer y así recibir toda la amarga herencia trágica del hombre. Pero muere, y tal conocimiento nunca llega al pueblo, el que desde su ignorancia sacraliza al joven "de gran hermosura", que articula absurdos obvios como "el curso de las cosas es el resultado de la voluntad libre de Dios",

Vallejo ve tal falta de comprensión como base de los defectos de la sociedad. La pérdida de la fe en la palabra impide que el hombre vea la verdad, aunque la encuentre ante los mismos ojos. Así sucedió, en la misma parábola, en el caso del doctor rabino que leía en el templo a Lenín (anacronismo éste muy eficaz) sin comprender la situación del pobre 
acreedor sirio a quien se le juzgaba. Pero lo más peligroso para el hombre no es la capacidad de la palabra de esconder la verdad, sino la de crear una" "verdad' 'falsa. Al oír los elogios del pueblo, el joven filosofastro respondió " como si acabase de tener una revelación por espacio de treinta años esperada". Y luego, la ironía que encarna la moraleja: "En torno de su cabeza judía, empezó a diseñąrse un azulado resplendor' ' (p. 66).

Si la personalidad humana ha de ser una, orgánica, el lenguaje también ha de ser orgánico, en el sentido de fiel a la verdad, con la que se une, y hasta se identifica. Lo absurdo, por su parte, no viene a ser un defecto de la existencia, sino un reflejo de la incapacidad de la lógica de captar la existencia en su unidad secreta, la que sólo puede captar el arte y el método dialéctico. Otro aspecto de la unidad de la existencia es la solidaridad humana, que también es orgánica. La ausencia de esa solidaridad en el mundo contemporáneo, según $V$ allejo, se debe a los defectos ya notados: la escisión de la personalidad humana, la exaltación de la razón, la traición de la palabra, y, no menos importante, una herencia cultural y económica que fomenta el egoísmo del individuo. Por eso, en un pasaje que nos recuerda el poema "Agape"'de Los heraldos negros, Vallejo lamenta la imposibilidad de sumergir su propio individualismo y asumir de alguna manera la totalidad de la existencia, alcanzando así la pérdida de sí mismo en "el otro":

Quiero perderme por falta de caminos. Siento el ansia de perderme definitivamente, no ya en el mundo ni en la moral, sino en la vida y por obra de la vida.

(Contra el secreto, p. 37)

Es el sentido de otra parábola del libro, "Individuo y sociedad", en la que reaparece el antiguo tema vallejiano del doble. En este caso, un asesino se salva por reconocerse a sí mismo en su doble, o sea, por reconocer su responsabilidad social y solidaria. Pero en el pasaje citado (tanto como en"Agape") Vallejo no encuentra una salida de su propio egoísmo (como tampoco la encontró el protagonista de la primera novela de Vallejo, Fabla Salvage, hecho que lo condenó) y termina el pasaje con una nota pesimista: "Esto es desesperante'" (p. 37).

Pero Vallejo iba a encontrar por fin una salida y su propia salvación en una actitud política que él denominaba socialista, término al que dio un sentido muy suyo y que desarrolló conceptualmente con más claridad en su obra El arte y la revolución. Esta obra-llamada su" "libro de pensamientos", según Georgette de Vallejo-- es la primera que inició después de sus dos viajes a la Unión Soviética. Siguió amplificándola a lo largo de 1930, y en 1932 la corrigió para entregarla a la Editorial Plutarco, la que rechazó el libro (Apuntes, p. 9). Es por eso que la primera página del original lleva la fecha, "Madrid febrero de 1932 ", pero también, "Paris 1934", lo que indica que Vallejo, después del rechazo, hizo nuevas correcciones. En efecto, es posible que nunca terminara los cambios que habia proyectado, puesto que dejó cinco notas al principio del texto (además de varias otras en el texto mismo), las que indican que seguía redactando el libro, o que por lo menos no quedaba en su forma definitiva. Pero tales cambios tenían por fin el desarrollo o ampliación 
de varios temas relacionados con el tema principal del libro: el complejo de relaciones entre el arte y la revolución. No representaban cambios de fondo en las materias esenciales del libro, de manera que podemos aceptar éste como el manifiesto definitivo de Vallejo sobre la cuestión del papel del arte y del artista en la revolución proletaria.

La mayor parte de los textos vienen de los artículos que Vallejo publicó en Mundial, Variedades, El Comercio y otras publicaciones, las más limeñas, desde 1926 a 1931. Como en el caso de mucios textos de Contra el secreto profesional, han sido refundidos, en la mayoría de los casos, extensamente. Una comparación con los originales demuestra el esfuerzo para enfocar la problemática que promete el título de tal manera que se podría justificar el activismo artístico en la revolución mundial del proletariado además que defender los dogmas de! arte, por no decir propaganda, de la revolución bolchevique.

Por medio de una comparación de los originales con las versiones refundidas, se puede entrever el drama de la lucha de Vallejo para poder poner su conciencia de artista de acuerdo con las necesidades cada vez más exigentes de su conciencia política, hasta que en la víspera de su primer viaje a la Unión Soviética pudo aceptar la necesidad del dogmatismo soviético en cuanto al arte de la revolución, sin aceptar, sin embargo, los criterios soviéticos en sí. Sólo después de sus dos viajes iba a encontrar la fórmula para apoyar la doctrina de Lenin sobre la literatura proletaria, pero de una manera muy suya.

Este drama comenzó con el artículo titulado "Los artistas ante la política", que publicó Vallejo en Mundial, el 30 de diciembre de 1927 (reproducido en Literatura y arte, pp. 4953). En este artículo, el que muy significativamente no aparece en El arte y la revolución, Vallejo rechazó la idea de que el poeta debe poner su arte al servicio de la política en forma de la propaganda, y criticó a Diego Rivera por querer prostituir el rol político del artista, “convirtiéndoloen el instrumento de un ideario político, en un barato medio didáctico de propaganda económica' '(p. 51). Aceptó, sin embargo, la sensibilidad politica del artista, la que no se somete nunca a una receta, sino que "se produce, de preferencia y en su máxima autenticidad, creando inquietudes y nebulosas políticas, más vastas que cualquier catecismo o colección de ideas expresas, y ... más puras que cualquier cuestionario de preocupaciones o ideales periódicos de política nacionalista o universalista' '(p. 50). El rol del artista "consiste, sobre todo, en remover, de modo oscuro, subconsciente y casi animal, la anatomía política del hombre despertando en él la aptitud de engendrar y aflorar a su piel nuevas inquietudes y emociones cívicas '(p. 50). Por fin, “todo catecismo politico, aún el mejor entre los mejores, es un disco, un cliché, una cosa muerta, ante la sensibilidad creadora del artista ... Las teorías, en general, embarazan e incomodan la creación' '(p. 52). Este último juicio iba a ser empleado por Vallejo para condenar el surrealismo, "una receta más de hacer poemas sobre medida", en su artículo "Autopsia del superrealismo", (publicado en Nosotros (Buenos Aires), LXVII, núm. 250 (mayo de 1930), 342-347, y reproducido, sin cambio alguno, en El arte y la revolución, pp. 72-79).

Casi un año más tarde, en septiembre de 1928, un mes antes de emprender su primer viaje a la Unión Soviética, Vallejo examinó, en un artículo intitulado "Literatura proletaria", el problema de la definición oficial del arte -- en la forma específica de una declaración por ordenanza administrativa de julio de 1925, por parte del gobierno soviético -- de la existencia de una literatura proletaria, que debería formar parte con todas las demás 
esferas sociales en la lucha de clases. Vallejo defendió el derecho y hasta la obligación del estado de constreñir a los escritores a orientarse, "de grado o por fuerza, dentro de los horizontes espirituales que convienen a sus concepciones políticas y sociales de la vida" (Literatura y arte, p. 76). El no hacerlo sería traicionarse a sí mismo, "sustrayendo a su ideal político un importante medio de realizarlo" "(p. 76). Pero a la vez afirmó la libertad del artista: "Sin embargo, muy diverso es y debe ser el concepto que los artistas tienen del arte" (p. 77). Luego Vallejo aclaró, al parecer una vez por todas, su propia actitud:

Cuando Haya de la Torre me subraya la necesidad de que los artistas ayuden con sus obras a la propaganda revolucionaria en América, le repito que, en mi calidad genérica de hombre encuentro su exigencia de gran grio político y simpatizo sinceramente con ella, pero en mi calidad de artista, no acepto ninguna consigna o propósito, propio o extraño, que aún respaldándose de la mejor buena intención, someta mi libertad estética al servicio de tal o cual propaganda política. Una cosa es mi conducta politica de artista, aunque, en el fondo, ambas marchan siempre de acuerdo, así no la parezca a simple vista. Como hombre, puedo simpatizar y trabajar por la Revolución, pero, como artista, no está en manos de nadie ni en las mías propias, el controlar los alcances políticos que pueden ocultarse en mis poemas.

(A rte y literatura, p. 77)

Vallejo siguió luego con una discusión sobre la naturaleza de la literatura proletaria, examinando primero la doctrina leninista de que el arte debería ser un instrumento del Estado para realizar una doctrina política, y luego la extensión de Trotski del "criterio proletario del arte a más vastos y profundos dominios del espíritu' '(p. 78). Al considerar la opinión de Trotski de que ningún artista hasta entonces había logrado realizar los trazos esenciales del arte proletario, Vallejo opinó que tal opinión fue "menos política y más humana que la del Soviet"'(p. 78), pero que en fin de cuentas ambos criterios "ven el arte, no desde un punto de vista estético y libre, sino desde un punto de vista político y dependiente del Estado"(p. 78). Reservó su juicio más negativo para condenar la actitud de Gorki, quien según Vallejo se confundía con el espíritu de la literatura burguesa por querer ensalzar al individuo y no a la masa como tal (p. 79). Por fin, terminó sus consideraciones en esta primera versión del artículo (publicado en Mundial, 28 de septiembre de 1928) con el dictamen de que la cuestión de lo que es la literatura proletaria todavía no había sido resuelto y que esto no sería posible mientras dominara en el debate "un criterio extraño a las leyes sustantivas del arte''(p. 80).

Ahora bien, la versión que figura en $E l$ arte y la revolucion $n$ ha sido refundida hasta tal punto que el énfasis del original se encuentra casi totalmente cambiado. Vallejo ha quitado todo comentario respecto al derecho del Estado de emplear el arte como instrumento ideológico; es decir, lo da por supuesto. Suprime, además, toda discusión en cuanto a la libertad estética del artista. Luego, después de incluir las referencias del original a Lenín, Trotski y Gorki, agrega una definición de la literatura proletaria como la propia literatura bolchevique, definición que demuestra que "una vez más, Lenín tiene aquí razón y la tiene 
sobre Trotsky, que pretende, por decirlo así, desviar y dispersar en vagos humanismos, el trabajo del artista proletario, y sobre Gorki, que, como escritor, debería ver estos problemas con mayor penetración técnica que los que no lo son" (El arte y la revolución, p. 60). Por fin, en unos párrafos totalmente nuevos, Vallejo desarrolla los conceptos de Lenín sobre la literatura proletaria, además de los suyos (v.gr. dos características esenciales del arte bolchevique o proletario son el "odio ardiente a la sociedad capitalista" y la disposición de "consagrar [el] talento [del artistaI a la destrucción de esta sociedad"), y termina afirmando rotundamente la obligación de tal literatura de "servir los intereses de clase del proletario y, especificamente...enmarcarse dentro de las directivas y consignas prácticas del Partido Comunista, vanguardia de las masas trabajadoras' '(p. 61).

Al parecer, Vallejo ha abandonado por completo su concepto de la libertad estética del artista y así ha traicionado su propia conciencia de artista. Así lo ve José Miguel Oviedo: "Estas nuevas versiones de los textos para homologarlos con las exigencias de su posición ideológica presente y con los apremios de la circunstancia política, muestra diversas fisuras, vacíos, contradicciones" ("Vallejo entre la vanguardia y la revolución", p. 9). Según Oviedo, la adscripción "sin restricciones" de Vallejo a la propuesta ideológica que contenía la "nueva utopia política" del comunismo a escala mundial le condujo a "una línea ortodoxa que aspira a ser todo lo férrea que se pueda...", pero que sin embargo "está quebrada en varias partes del libro" (p. 10). "Las certezas que Vallejo quiere asumir hasta sus últimas consecuencias, quedan contradichas por la tendencia- $\tan$ característica en el poeta-a explorar las experiencias y creencias a un nivel del espíritu más hondo y libre del quealcanzan las fáciles consignas y lemas de acción política'. Así se explica que "nos encontremos con conflictos irresolubles" (p. 10).

Sin duda Oviedo ha querido ver el asunto con la mayor generosidad al considerar las contradicciones básicamente como el drama del "proceso intelectual por el que atraviesa Vallejo al filo de la década del 30" (p. 10). "Pero dos consideraciones obran aquí para

\footnotetext{
${ }^{10}$ Con menos simpatía ha visto D. P. Gallagher la dicotomía aparente entre Vallejo el poeta y Vallejo el apologista del marxismo: en su estudio sobre el poeta, incluido en su obra Modern Latin American Literature (Oxford University Press, New York, 1973), enjuicia así la actitud política de Vallejo: "Vallejo came to be an extremely militant, indeed rather dogmatic, Communist in the thirties.... What is remarkable is that Vallejo never let his political faith significantly affect his poetry. Politics are present in many of the poems in Poemas bumanos, but always as just one new element in Vallejo's consciousness. Unlike Pablo Neruda, who...was prompted by militance wholly to abandon the hermetic, neurotic vision of Residencia en la tierra, Vallejo regards Communism, in Poemas bumanos and 'España, aparta de mí este cáliz', as just one more component of an essentially unchanged vision, just the vague sighting of a way out from a world that nevertheless remains as hermetically frontier-bound as that of Trilce. It would seem that Vallejo was too rigorous a man to believe in miracles; or conversely, that political affirmation outside his poetry was mostly just a necessary and convenient way of preserving his sanity. In order to arrive at the self-discovery that he was aiming for in his poems, he had to keep all his options open, however terrible. In his ordinary life he could take time off from so dangerous an enterprise and choose the option that seemed most promising to him. How else can one explain the almost schizophrenic gap that separates the relentless affirmations of the prose from the tortured neurosis of the poetry?"' (p. 29). Creemos con Gallagher que la cosmovisión de Vallejo no ha cambiado, pero el comunismo vallejiano significa mucho más que "un elemento más" de su cosmovisión. No es nuevo el sentido político de su poesía, ni tampoco existe un abismo esquizofrénico entre su prosa y su poesía, aunque sí existen unas diferencias esenciales entre sus medios y fines. En cuanto a la adhesión de Vallejo al marxismo, hay que definir bien el significado que se da al término "dogmático"; si quiere decir que Vallejo es un partidario entusiasta de la experiencia bolchevique, tiene razón Gallagher; pero como veremos, el socialismo vallejiano sobrepasa los conceptos de la dictadura proletaria, la que, en su turno, es sólo el primer paso hacia el socialismo, última solución política de la raza humana. La defensa por Vallejo del gobierno soviético es más bien pragmática que dogmática, y como veremos, Vallejo hasta condena a los marxistas dogmáticos.
} 
impedir que a Vallejo se le disculpe por completo la existencia de estas contradicciones. En primer lugar, al parecer existen lado a lado en una sola obra, lo que indica un descuido muy grave y hasta un abuso del lector. En segundo lugar, es difícil aceptar lo aparentemente causístico de tal cambio de actitud respecto a un asunto tan grave como es el de la integridad artística.

Por de pronto, las contradicciones empiezan a desvanecerse si atendemos bien a los términos que emplea Vallejo. En primer lugar, Vallejo no distingue entre comunismo y socialismo: "Ese nuevo orden social, que ha de reemplazar al actual, no es otro que el orden comunista o socialista. El puente entre ambos mundos: la dictadura proletaria' ( $E l$ arte y la revolución, p. 17). Pero es obvio, por esta misma cita, que Vallejo sí distingue entre socialismo (o comunismo) y la dictadura proletaria (el gobierno soviético). Esta es sólo la primera etapa en el desarrollo del verdadero socialismo: "El fenómeno soviético es la demostración objetiva, palmaria y de un realismo inexorable, del camino dialéctico ineludible que ha de seguir el sistema social capitalista para desembocar en el orden socialista [... ] los obreros y campesinos del inmenso país de los Soviets...echan las bases de una nueva sociedad socialista"' (pp. 17-18).

Pero también es obvio, nos parece, que tal sociedad no ha llegado a su perfección todavía. Para Vallejo, la utopía socialista se encontraba en el futuro, aunque han existido y existen ahora formas socialistas de la vida que prometen algún día, destruidos los antagonismos del sistema capitalista, florecer en el socialismo verdadero:

Aunque andamos aún lejos de la sociedad socialista, no podrá negarse que existen diversos aspectos de la vida social, cuya forma, estructura e irradiación colectivas son manifiestamente socialistas. Ejemplos: la técnica de producción en cadena, el motocultivo, el combinat y otras formas avanzadas del trabajo; el tipo standard de gran número de productos industriales, muchas costumbres cotidianas, las grandes viviendas obreras, y finalmente, el gran arte. Se trata, desde luego, de formas socialistas rudimentarias e incompletas dado que se hallan frenadas por los antagonismos del sistema capitalista en que se producen. La masa misma es acaso la forma más sugestiva, por ahora, de vida socialista. El socialismo se halla, pues, en marcha, encarnado en múltiples fenómenos de la vida social .

(El arte y la revolución, p. 39)

Para Vallejo, el elemento primordial del socialismo es la masa o colectividad, en que el egoísmo del individuo tiene que ceder a las exigencias de la vida colectiva: "Indudablemente, no se puede hablar de socialismo ni de arte socialista, en sociedades en que el hombre es explotado por el hombre"' (p. 40). Por eso, la revolución proletaria es el primer paso hacia tal sociedad:

La sociedad socialista no va a surgir de golpe, de la noche a la mañana. La sociedad socialista será el resultado de todo el proceso social de la historia. La sociedad socialista será la obra de un conjunto de fuerzas y leyes deterministas de la vida social. Ella no será una improvisación, sino una elaboración racional y científica, lenta, evolutiva, cíclica y revolucionaria. La prueba está en que la 
estamos viendo ahora (concretándose y definiéndose en Rusia) y la hemos visto, en el pasado plural y sucesivo de las sociedades, esbozarse y edificarse piedra a piedra.... (p. 39)

Sin la revolución proletaria, la elaboración "científica"' del socialismo es una imposibilidad:

La división de la sociedad en clases y el imperio de la injusticia han impedido, ciertamente, hasta hoy, una más vasta, profunda y pura socialización de muchos aspectos de la vida colectiva (p. 41)

Sin embargo, el momento es propicio para tal socialización:

...la dialéctica irrefragable de la historia, contrariando y triunfando de las clases dominantes, ha socializado, repito, ciertas formas sociales de la vida. Es así como los Estados Unidos, baluarte por excelencia del sistema capitalista--con sus injusticias más refinadas--ofrecen en su técnica de trabajo y en su estructura industrial, una creciente, aunque sorda y subterránea, tónica socialista (p. 41).

De ahí la gran importancia de la experiencia soviética:

En grado revolucionario y sumo, Rusia--con la abolición de clases y la supresión de la injusticia social--ha cerrado el ciclo de las socializaciones esporádicas, intermitentes y larvadas y ha abierto para siempre la era socialista de la humanidad. Y mañana, cuando haya estallado y triunfado la revolución proletaria universal, la sociedad será socializada integralmente, no sólo en la producción, sino también y lo que es más decisivo, en la distribución de los productos (p. 41).

Sin entrar en la cuestión de la objetividad con que Vallejo enjuicia la dictadura soviética, podemos comprender la importancia que da Vallejo a la revolución proletaria: es el único medio de derrocar el egoísmo burgués que se encuentra ínsito en el sistema capitalista. Por ser imprescindible tal revolución, se justifica el empleo del arte soviético " como medio de realizar el socialismo y como una fuerza dialéctica de creación de aquella sociedad'” (p. 43). Pero, ¿puede considerarse o caracterizarse ese arte como arte socialista?

...tomado el arte soviético como medio de realizar el socialismo y como una fuerza dialéctica de creación de aquella sociedad, ese arte puede considerarse o, mejor dicho, caracterizarse como socialista. En segundo lugar, tomado el arte soviético como reflejo y expresión de la sociedad de que procede, también puede caracterizarse como socialista, puesto que él encierra, repetimos, muchas y fundamentales formas, socializadas ya, de la vida colectiva. 
Pero, juzgadas las cosas con mayor precisión, es imposible no percibir, a la base del arte y la literatura soviéticos, todo el espíritu y todos los caracteres de lo que más adelante hemos designado con el nombre de arte bolchevique (subrayamos). Más que expresar las formas de una nueva sociedad, socializada en un $25 \%$ o $30 \%$, el arte soviético se propone, de preferencia, atizar y adoctrinar la rebelión y la organización de todas las masas del mundo, para la protesta, para las reivindicaciones, para la lucha de clases y para la revolución universal (p. 44).

Así queda claro el hecho de que Vallejo distingue el arte por su funcion y por el alcance de sus conceptos, sentimientos e ideas. Por eso puede considerar la música de Beethoven y la obra de Bach como arte socialista (p. 37):

Estos músicos llegaron, en efecto, a tocar lo que hay de más hondo y común en todos los hombres, sin aflorar a la periferia circunstancial de la vida (subraya el autor ), zona ésta que está determinada por la sensibilidad, las ideas y los intereses clasistas del individuo (p. 42).

Vallejo enumera los siguientes tipos de arte: proletario o bolchevique, socialista y burgués o capitalista. En otro lugar, el pasaje intitulado "Ejecutoria del arte bolchevique", Vallejo no vacila en juzgar y situar en sus fines, sin ofuscación alguna, al arte bolchevique o proletario:

El arte bolchevique es principalmente de propaganda y agitación...Sus fines son didácticos, en el sentido específico del vocablo. Es un arte de proclamas, de mensajes, de arengas, de quejas, cóleras y admoniciones. Su verbo se nutre de acusación, de polémica, de elocuencia agresiva contra el régimen social imperante y sus consecuencias históricas. Su misión es cíclica y hasta episódica y termina con el triunfo de la revolución mundial...Al iniciarse la edificación socialista mundial, cesa su acción estética, cesa su influencia social (p. 26).

Luego de señalar el carácter' utilitario y propagandista del arte bolchevique, Vallejo hace una distinción clave entre este "arte temporal" y el arte socialista, "arte intemporal" :

El arte bolchevique, por su prestancia actualista fulminante, requiere y embarga la atención colectiva más que el arte socialista. Siempre el arte temporal predomina, en el momento del que procede y al que sirve, sobre el arte intemporal (p. 27).

Aclaradas las características del "arte" o propaganda bolchevique, quizás podemos entender por qué Vallejo pudo elogiar, en las palabras de José Miguel Oviedo, "un tipo de arte en el que de ninguna manera es posibie reconocer al poeta de Poemas bumanos", ("Vallejo entre la vanguardia y la revolución", p. 9). E1 cjemplo que da Oviedo es el pasaje en que Vallejo habla de la superiorıdad ae la nu:'eva psicología colectiva en Rusia sobre la psicología burguesa, citando mumentos decisivos del arte bolchevique: 
¡Qué lejos del tartufismo, de la "delicadeza" convencional y ñoña y de la vergüenza burguesa. En una pieza teatral, un hombre ordena el fusilamiento de su hermano, en nombre del interés revolucionario. En una novela, una mujer solicita y obtiene de las autoridades que el hijo que acaba de dar a luz, sea suprimido, en virtud de haber nacido estropeado. . . (p. 52).

Sin aceptar el dictamen de Vallejo, se podría entender cómo llega a tal juicio teniendo en cuenta no sólo la supremacía que otorga al bienestar colectivo respecto al sentimiento egoísta o individualista, sino también el hecho de que Vallejo califica al arte bolchevique por criterios distintos de los criterios con que enjuicia lo que él llama arte socialista, que viene a ser el único arte verdadero. En sus definiciones del artista socialista y del arte socialista, si podemos reconocer al poeta de Poemas bumanos:

El poeta socialista no reduce su socialismo a los temas ni a la técnica del poema. No lo reduce a introducir palabras a la moda sobre economía, dialéctica o derecho marxista, a movilizar ideas y requisitorias politicas de factura u origen comunista, ni a adjetivar los hechos del espíritu y de la naturaleza, con epítetos tomados de la revolución proletaria. El poeta socialista supone, de preferencia, una sensibilidad orgánica y tácitamente socialista. Sólo un hombre temperamentalmente socialista, aquel cuya conducta pública y privada, cuya manera de ver una estrella, de comprender la rotación de un carro, de sentir un dolor, de hacer una operación aritmética, de levantar una piedra, de guardar silencio o de ajustar una amistad, son orgánicamente socialistas, sólo ese hombre puede crear un poema auténticamente socialista. Sólo ése creará un poema socialista, en el que la preocupación esencial no radica precisamente en servir a un interés de partido o a una contingencia clasista de la historia, sino en el que vive una vida personal y cotidianamente socialista (digo personal y no individual). En el poeta socialista, el poema no es, pues, un trance espectacular, provocado a voluntad y al servicio preconcebido de un credo o propaganda política, sino que es una función natural y simplemente humana de la sensibilidad (pp. 28-29).

El poeta socialista viene a ser el verdadero poeta de quien ha hablado siempre Vallejo, y quien ha hablado desde el principio en la poesía de Vallejo. Así que hay que entender el calificativo socialista en el sentido de lo más profundamente humano de la personalidad, el yo que tiene todo ser humano y que representa precisamente lo más esencial y característicamente humano."

Por la misma distinción entre arte proletario o bolchevique, arte socialista, y arte burgués, se puede entender su rechazo de la literatura burguesa, hecho que asombra a Oviedo: “...movido por el afán de exaltar la grandeza de la literatura proletaria, (Vallejo)

\footnotetext{
"Vallejo distingue este yo esencial, que se identifica con la humanidad, del egoismo del individuo. El yo es personal, atributo de la persona humana, mientras el egoísmo es atributo del individuo, y por eso contingente. Es: al parecer, el sentido de "Voy a hablar de la esperanza"' de Poemas bumanos: "Yo no sufro este dolor como César Vallejo. Yo no me duelo ahora como artista, como hombre ni como simple ser vivo siquiera. Yo no sufro este dolor como católico, como mahometano ni como ateo. Hoy sufro solamente..." (OPC, p. 243). La causa de un dolor tar profundo está por debajo de todo aspecto contingente; es algo intrínsico a la condición humana.
} 
rechaza violentamente toda la literaturaburguesa" ("Vallejo entre la vanguardia y la revolución', p. 11). Vallejo la condena en estas palabras: "En los temas y tendencias de la literatura burguesa no hay más que egoísmo y desde luego, sólo los egoístas se placen en hacerla y en leerla' '(El arte y la revolución, p. 96). Una vez entendidas las distinciones que hace Vallejo, se comprende que, según su definción, la 'literatura burguesa' no se identifica estrechamente con toda la literatura de la saciedad capitalista. Al contrastar la literatura de espiritu colectivo con la burguesa, Vallejo declara en su ensayo, "Duelo entre dos literaturas" (publicado primero en Universidad, Universidad de San Marcos, Lima $1^{\circ}$ de octubre de 1931):

Digo producción obrera, englobando en esta denominación a todas las obras en que dominan, de una u otra manera, el espíritu y los intereses proletarios: por el tema, por su contextura psicológica, o por la sensibilidad del escritor. Así es como figuran dentro de la literatura proletariz autores de diversa procedencia clasista, tales como Upton Sinclair, Gladkov, Selvinsky, Kirchon, Pasternak, O'Flaherty y otros, pero cuyas obras están, sin embargo, selladas por una interpretación sincera y definida del mundo de los trabajadores.

(El arte y la revolución, p. 98)

Así también Vallejo salva a Tolstoi y a Dostoievski, por ejemplo, pero condena al poeta bolchevique Maiakovski y a Gorki. Es decir, Vallejo enjuicia la obra misma del artista, y no la etiqueta que lleva el producto artístico, ni la receta que proclama el artista: "Las declaraciones de Maiakovski expresan la verdad sobe su obra en el sentido en que confirman el hecho de que ella responde a un arte basado en fórmulas y no en la sinceridad afectiva y personal"'(p. 109).

Sin percibir tales distinciones, Oviedo llega a la calificación siguiente : "Se diría que en El arte y la revolución trata de elaborar una teoría-marxista del arte que no es sino un pálido ensayo de lo que su poesía pone admirablemente en ejercicio; es decir, la verdadera teoría de Vallejo es su praxis poética' ' 'Vallejo entre la vanguardia y la revolución', p. 12). Pero, en el fondo, la definción vallejiana del arte socialista, o sea, del arte verdadero, es su teoría de siempre, hecho que justifica la presencia en $E l$ arte $y$ la revolución de varios textos publicados anteriormente, textos en los que podemos estudiar la poética de Vallejo antes de su adhesión al marxismo.

Tal es el caso del texto, "Electrones de la obra de arte', en el que Vallejo recoge algunos párrafos claves de su artículo," "La nueva poesía norteamericana"; publicado en $E l$ Comercio, 30 de julio de 1929 (y reproducido en Aula 5-6-7, 67-70). En el original Vallejo elogia a ciertos poetas jóvenes de Norteamérica, por expresar "un estado de espíritu colectivo...y de inquietud social', pero la mayor parte del artículo se dedica a las teorías de Vallejo sobre la palabra poética, materia prima de la poesía, y lo intraducible de la poesía. En la forma en que figura en El arte y la revolución, no queda mención alguna de la poesía norteamericana; se ha agregado, además; uñ párrafo final sobre lo orgánico y lo elemental de las materias primas empleadas en la arquitectura, la música, el cine, etc. (pp. 69-71). Otro ejemplo es "Poesía nueva', publicadó originalmente en Favorables-ParisPoema, núm. 1, julio de 1926, y reproducido íntegramente aquí. Vallejo critica el empleo de vocablos de la ciencia y las industrias contemporáneas (radio, motor, jazz-band) cuando 
todavía "los materiales artísticos que ofrece la vida moderna...(no han) sido asimilados por el artista y convertidos en sensibilidad"'(p. 100). Critica también, y por las mismas razones, la poesía a base de metáforas nuevas (p. 101). Su conclusión alude a lo que en otra parte él llamaria poesía socialista:"La poesía nueva a base de sensibilidad nueva es, al contrario, simple y humana y, a primera vista, se la tomaria por antigua o no atrae la atención sobre si es o no es moderna" (p. 101).

Hasta un texto nuevo como el breve "Regla gramatical" no aporta nada nuevo a la poética de Vallejo, aunque expresa de otra manera ciertos aspectos de su poética y hace más explicito su concepto de la libertad estética del artista:

El poeta puede hasta cambiar, en cierto modo, la estructura literal y fonética de una misma palabra, según los casos. Y eso, en vez de restringir el alcance socialista y universal de la poesía, como pudiera creerse, lo dilata al infinito. Sabido es que cuanto más personal (repito, no digo individual) ${ }^{12}$ es la sensibilidad del artista, su obra es más universal y colectiva (p. 64).

Aunque el empleo de la voz socialista es un elemento nuevo, Vallejo había hablado antes sobre la validez de una nueva estética en su artículo, "Los maestros del cubismo', publicado en Variedades, 25 de agosto de 1928 (reproducido en Literatura y arte, pp. 67-71). Vallejo dijo lo siguiente:

La difusión del cubismo prueba únicamente que en él alienta un contenido ampliamente humano, una vitalidad universal. Esta difusión es, por lo mismo, natural y lógica. Las grandes corrientes estéticas de la historia han tenido idéntica suerte e igual consagración (p. 69).

En cuanto a la necesidad del artista de expresar lo más personal de su sensibilidad para hacer más universal y colectiva su obra, Vallejo dio en el mismo artículo el siguiente juicio sobre èl pintor español Juan Gris:

Gris es siempre Gris, contra ases y senas, aún contra el tiempo y contra sí mismo. Y por este riguroso espíritu de austeridad artística y por la posesión científica de sus fuerzas creadoras, sin nieblas inconfesables ni misterios rebuscados y cómplices, Juan Gris quedará como el pintor más representativo de nuestra época (p. 71).

Otro pasaje, "Poesía e impostura", es una versión levemente refundida de una parte de "Se prohibe hablar al piloto", publicado en Favorables-Paris-Poema, núm. 2, octubre de 1926 (reproducido en Literatura y arte, pp. 21-23), la que empieza: "Hacedores de imágenes, devolved las palabras a los hombres..." En la versión definitiva, Vallejo ha agregado un nuevo título que da más énfasis al sentido básico del pasaje, además de una nueva frase inicial: "Hacedores de símbolos, presentaos desnudos en público y sólo

12 Cf. la nota 11. 
entonces aceptaré vuestros pantalones". También ha cambiado la frase final del original: "Fraguadores de colmos, os conmino a presentaros de manos y una vez hecho esto, ya podéis hacer lo demás"' (Literatura y arte, p. 22). A hora se lee: "Hacedores de colmos se ve de lejos que nunca habéis muerto en vuestra vida", una muestra del desprecio que sentía Vallejo hacia los autores de "literatura de gabinete" que no habían compartido nunca la miseria de los desprovistos del mundo. Pero quizás lo más importante es la nota al pie de la página: 'Poesía e impostura: añadir que el 'hacedor' debe ser reemplazado por el conductor de vida social y de dolor derivado del capitalismo..." (El arte y la revolución, p. 63), es decir, por el poeta socialista, en el sentido del término que le da Vallejo.

Sin cambiar en lo esencial su poética, Vallejo buscaba dar un enfoque más preciso al aspecto" "político" de su pensamiento. Otro ejemplo que ilustra este esfuerzo es la refundición del conocido pasaje sobre la naturaleza del poema, que en un principio formaba parte del mismo" Se prohibe hablar al piloto":

Un poema es una entidad vital mucho más orgánica que un ser orgánico en la naturaleza. A un animal se le amputa un miembro y sigue viviendo. A un vegetal se le corta una rama y sigue viviendo. Pero si a un poema se le amputa un verso, una palabra, una letra, un signo ortográfico, MUERE.

(Literatura $y$ arte, p. 21)

Agrega lo siguiente en la versión definitiva:

Como el poema, al ser traducido, no puede conservar su absoluta y viviente integridad, él debe ser leído en su lengua de origen, y esto, naturalmente, limita, por ahora, la universalidad de su emoción. Pero no hay que olvidar que esta universalidad será posible el día en que todas las lenguas se unifiquen y se fundan, por el socialismo, en el único idioma universal. (El arte y la revolución, p. 62)

La poética en sí no ha sufrido ningún cambio aquí; ya hemos visto el dictamen de Vallejo sobre lo intraducible de la poesía. Pero lo agregado tiene por motivo llevar la poética hacia una finalidad política, en el sentido más amplio de esta palabra.

Sin embargo, parece irresoluble la contradicción entre esta poética esencial de Vallejo, y lo que afirma en el artículo con que concluye $E l$ arte y la revolución, "El arte revolucionario, arte de masas y forma específica de la lucha de clases', (pp. 122-125). Anteriormente, en la obra, en el trozo “QQué es un artista revolucionario?", Vallejo habia definido así a' 'todo verdadero artistá': 'Revolucionario, política y artísticamente, es y debe ser siempre todo artista verdadero, cualquiera que sea el momento o la sociedad en que se procede"'(p. 24). Pero también había separado al artista soviético por tener éste la responsabilidad de "no obrar contra la revolución socialista naciente, sino ... (de) servirla e impulsarla"'(p. 24). Es decir, "el estudio objetivo y científico de la historia" dictaba que el artista, tal como se encontraba en la Unión Soviética, debiera suspender su rol revolucionario tradicional para apoyar la versión oficial del arte. Son dos las justificaciones de este deber. En primer lugar los artistas soviéticos "son revolucionarios precisamente porque son los pioneers de esa gran revolución', y en segundo lugar, "es en un plano mundial que los artistas soviéticos ejercen su función revolucionaria, y, en este plano, el régimen social dominante es el capitalismo, contra el cual la única manera que tienen esos 
artistas de ejercer su función revolucionaria, es trabajando según los principios e intereses soviéticos, que son los intereses y principios revolucionarios mundiales' '(pp. 24-25).

Vallejo separa también al artista bolchevique del artista socialista, el que, como hemos visto, crea el arte intemporal, considerado el arte verdadero por Vallejo: "Sólo desde un punto de vista dialéctico es que puede denominarse y se denomina socialista al artista bolchevique' '(p. 25). Es decir, Vallejo no quiere identificar el arte bolchevique, lo que él ha llamado propaganda, con el arte verdadero, y para resolver el dilema, acude al concepto del desarrollo dialéctico del arte. En tanto que la revolución proletaria conduciría a la utopía socialista, el arte proletario conduciría al arte socialista. ${ }^{13}$

Es desde este punto de vista como se puede entender mejor el artículo que cierra el libro. Urgido por los problemas del " actual período social de la historia, por la agudeza, la violencia y la profundidad que ofrece la lucha de clases", Vallejo declara que la sensibilidad del artista no puede sustraerse a ellos, y llega a la conclusión de que "decir...arte y, más aún arte revolucionario, equivale a decir arte clasista, arte de lucha de clases', y que 'artista revolucionario en arte, implica artista revolucionario en política' '(p. 122). El arte que crea debe ser de un "realismo implacable...arte de primer plano...todo crudo...ángulos y no curvas, pero pesado, bárbaro, brutal, como en las trincheras"'(pp. 123-124).

La identificación del arte revolucionario con el arte proletario parece aquí completa, pero al estudiar bien la conclusión del artículo, surgen algunas dudas. Al referirse al público de este arte, Vallejo destaca el hecho de que es "múltiple: la masa aún no radicalizada y que forma en las filas del fascismo o del anarco-sindicalismo y hasta de los partidos de izquierda burgueses; la masa sin conciencia clasista, la masa ya radicalizada y bolchevique, y, por último, la pequeña burguesía y la propia alta burguesiá'(p. 125). Es por eso que una táctica fina, hábil, aguda y dúctil hay que observar en este terreno, ya que el objetivo práctico de la obra artística o literaria depende de los medios que se emplean para cada público y según las necesidades del instante" (p. 125). En otras palabras, Vallejo parece modificar cualquier concepto de una "receta artística" a la que parece señalar el articulo, para dejar lugar a un arte revolucionario multiforme que implica la libertad estética del artista. Está claro, de todos modos, que ha vuelto definitivamente a tal actitud hacia el final de su vida. En uno de los apéndices de la obra, "El carnet de 1936-37-¿38?", declara Vallejo:

Hay la literatura revolucionaria rusa y la literatura revolucionaria que combate dentro del mundo capitalista. Los objetivos, método de trabajo, técnica, medios de expresión y materia social varía de la una a la otra. Esta distinción nadie la ha hecho todavía dentro de la critica marxista (p. 156).

\footnotetext{
${ }^{13}$ Recordemos también que el arte proletario sirve los intereses clasistas del proletariado, según Vallejo, mientras el arte socialista no sirve a "un interés de partido o a una contingencia clasista de la historia" (El arte $y$ la revolución, p. 28). El arte socialista es "una función natural y simplemente humana de la sensibilidad" (p. 29).

${ }^{14}$ Después de todo, es el mismo punto de vista que expresa Vallejo en varios momentos de la obra, algunos de los cuales citamos en este estudio. Es posible interpretar este último artículo como una llamada a los artistas a hacer propaganda, sobre todo cuando la definición que emplea Vallejo para arte revolucionario, "arte de lucha de clases", es la misma que emplea para arte bolchevique en otros instantes de la obra. De todos modos, la distinción que hace entre las dos literaturas no parece caber dentro de la teoría crítica de Lenín y Engels, según Georg Lukács; para
} 
Sin duda la pasion pulítica de Vallejo lo llevó peligrosamente cerca de una negación terminante de la libertad estética del artista, pero se salvó en último término, no sólo por medio de las salvedades aludidas, sino por el ejemplo de su propia praxis poética. ${ }^{15}$

La importancia de El arte y la revolución se encuentra sobre todo en poner de manifiesto el pensamiento político de Vallejo durante la época de su conversión al marxismo, o sea, desde fines de 1928 hasta el principio de 1930, y también el desarrollo de este pensamiento en los años inmediatamente después de su conversión. Nos da la clave de su fe en el marxismo y en la filosofía del materialismo dialéctico, además de su profundo interés por la experiencia soviética. ${ }^{16}$ Pero quizás el aspecto más dramático de la obra es la evidencia que nos da de la lucha íntima de Vallejo para lograr un equilibrio entre exigencias

ellos, todo verdadero arte tiene la misma naturaleza: "We have already seen how for Lenín and Engels partisanship [human practice in interrelationship with the external world] in the work of art is a component of objective reality and of a correct, objective artistic reflection of life. The tendency in the work of art speaks forth from the objective context of the world depicted within the work; it is the language of the work of art transmitted through the artistic reflection of reality and therefore the speech of reality itself, not the subjective opinion of the writer exposed baldly or explicitly in a personal commentary or in a subjective, ready-made conclusion. The concept of art as direct propaganda, a concept particularly exemplified in recent art by Upton Sinclair, rejects the deeper, objective propaganda potential of art in the Leninist conception of partisanship and substitutes pure personal propaganda which does not grow organically out of the logic of its subject matter but remains a mere subjective expression of the author's views' (The Writer E Critic and Otber Essays, Georg Lukács, trans. and ed. by Arthur D. Kahn, Grosset and Dunlap, New York, pp. 43-44).

${ }^{15}$ No puede decirse lo mismo en cuanto a su obra novelística y dramática. La novela Tungsteno, publicada en marzo de 1931 (Madrid, Editorial Cénit), además de Colacbo Hermanos, fragmento dramático sobre el tema de Tungsteno del imperialismo yanqui y la obra dramática Moscu contra Moscu (definitivamente Entre las dos orillas corre el rio) manifiestan bien a las claras sus aspectos polémicos y su naturaleza de obras de tesis, características que en muchos momentos suelen quitar el valor estético de las obras, por la concentración sobre lo que Georg Lukács ha llamado el que del contenido a expensas del como, la manera de articular y fijar estéticamente las reacciones humanas al mundo. Tal reducción de la obra literaria a una sola dimensión no ocurre en su poesia, donde el que y el como forman una unidad indisoluble, el estilo único del poeta Vallejo.

16 'f. Roberto Paoli, “Observaciones sobre el indigenismo de César Vallejo", Revista Iberoamericana, XXXVI, núm. 71 (abril-junio 1970), 341-344. En este estudio breve pero muy sugestrvo, Paoli plantea el indigenismo de Vallejo como causa principal de su "entusiasmo, tan confiado que raya en lo acrítico" por la nueva sociedad bolchevique. Según Paoli, el indigenismo vallejiano tiene muchos puntos de contacto con el manifestado por José $\mathrm{C}$. Mariátegui en su obra, Siete ensayos de interpretación de la realidad peruana. En las palabras de Paoli, es "...un indigenismo...en el que se entretejen realidad y mito, y en el peculiar ambiente de los años veinte y treinta, cuando...la mitología dieciochista, aunque nominalmente rechazada (por el marxista Mariátegui, por ejemplo), concordaba de hecho con los primeros análisis económicos y sociológicos de la realidad peruana, en virtud de sus gérmenes sentimentales e ideales, en virtud de los arquetipos humanos que anoraba y anhelaba como valores representantes de un pasado perdido que se renovaria en el futuro, en virtud precisamente de sus mitos nostálgicos y proféticos" (p. 342). Al llegar Mariátegui a la conclusión de que el indio era todavta (o ya) comunista, llegó a concluir también que había que reactivar el proceso histórico del indio, paralizado por los blancos. Vallejo, a diferencia de Mariátegui, "...concretó históricamente el mito del hombre nuevo, del hombre solidario e interhumano (plasmación final que reproducía los caracteres del patrón original), proyectándolo y encarnándolo en el bolchevique revolucionario". Así que “...cuando visitó Rusia, vio la sociedad soviética con ojos de indio..." (p. 343). Paoli señala, además, que en el culto a Rusia se injerta otro motivo que se combina con el marxismo y el indigenismo de Vallejo: "...un cristianismo auténtico que suscita en [el espíritu ruso] grandes y cósmicas exigencias de justicia humana. Es el espiritu cristiano de Dostoievski, autor que Vallejo admiraba tanto y cuya influencia sobre algunos temas e incluso sobre algunos enunciados de Poemas humanos y de Espana, aparta de mi este cáliz hay que tomar en seria consideración" (p. 344). Ya hemos notado la opinión de Vallejo sobre Dostoievski, a quien Vallejo elogia en El arte y la revolación. Las observaciones de Paoli concuerdan muy bien con la opinión de José Miguel Oviedo de que el marxismo fertilizó la poética de Vallejo, pero también con nuestro juicio, contrario al de Oviedo, de que no renovó su poética en su esencia. E1 aspecto "político" de ésta, en el sentido más amplio del término, se encontraba ya en la herencia cultural de Vallejo. 
y necesidades del hombre político y la integridad artística del poeta. Se salva éste por medio de una poética que nunca abandona. Si ha querido otorgar cierto valor e importancia a la propaganda soviética llamándola arte proletario o bolchevique, no ha alcanzado a darle una base teórica -- no hay en la obra el desarrollo sistemático de una teoría estética marxista -sino que sólo ha destacado el fin utilitario y ha afirmado la necesidad pragmática de la propaganda bolchevique. Pero ha reiterado lo esencial de su verdadera poética, la que conduce al arte verdadero, o arte socialista, para emplear la terminología que se manifiesta por primera vez en esta obra. Esta poética no se deja influir por el marxismo, pero sin embargo encuentra en el marxismo y en la experiencia soviética un enorme sustento espiritual. El gran valor de lo absurdo, postulado básico desde Trilce, encuentra ya su base filosófica por excelencia en el materialismo dialéctico; todo instante de lo absurdo viene a ser lo que Vallejo llama en Rusia ante el segundo plan quinquenal, “...una contradicción dialéctica...una contradicción en movimiento y en marcha hacia una solución " $(R u$ sia ante el segundo plan quinquenal, 1a ed., Editorial Gráfica Labor, Lima, 1965, p. 239).

Por medio de la misma teoría, Vallejo encuentra una base filosófica que puede ofrecerle la posibilidad de alcanzar la plenitud orgánica que ha buscado a lo largo de su trayectoria poética. Le ofrece una salida, ya fuera de su expresión poética, de la lógica tradicional de la existencia y le abre el camino hacia un porvenir utópico. Sin embargo, queda probado textualmente, a nuestro juicio, la existencia en su forma esencial de la poética vallejiana antes de su adhesión al marxismo, hecho que quizás explica en parte el que su poesía no cayera en la mera propaganda.

Estas dos obras, aunque no alcanzan la unidad y desarrollo estéticos (lo fragmentario, repetido y descontinuo de la forma de estas obras, aspectos que son positivos en el mosaico que es Poemas bumanos, resultan defectos aquí) que les merecieran considerarse importantes por sus valores literarios, son sumamente importantes para los lectores de Vallejo que buscan una mayor comprensión de su vida intelectual durante los últimos años de sti vida. Constituyen los dos primeros volúmenes de sus futuras Obras completas, que continuarán con tomos dedicados a su poesía, su narración, su teatro, etc. y representan en sí un gran paso hacia una definitiva imagen literaria y humana de Vallejo. 